\title{
Serum osteoprotegerin/osteoclastogenesis-inhibitory factor during pregnancy and lactation and the relationship with calcium- regulating hormones and bone turnover markers
}

\author{
H Uemura, T Yasui, M Kiyokawa, A Kuwahara, H Ikawa, \\ T Matsuzaki, M Maegawa, H Furumoto and M Irahara
}

Department of Obstetrics and Gynecology, University of Tokushima, School of Medicine, 3-18-15, Kuramoto-cho, Tokushima 770-8503, Japan

(Requests for offprints should be addressed to H Uemura; Email: uemura@clin.med.tokushima-u.ac.jp)

\begin{abstract}
Pregnancy and lactation induce dynamic changes in maternal bone and calcium metabolism. A novel cytokine termed osteoprotegerin (OPG)/osteoclastogenesisinhibitory factor (OCIF) was recently isolated; this cytokine inhibits osteoclast maturation. To define the effects of pregnancy and lactation on circulating OPG/OCIF in mothers, we studied the changes in the levels of OPG/ OCIF as well as those of calcium-regulating hormones and biochemical markers of bone turnover in the maternal circulation during pregnancy (at 8-11 weeks, at 22-30 weeks, at 35-36 weeks and immediately before delivery) and lactation (at 4 days and at 1 month postpartum).

Serum intact parathyroid hormone levels did not change and were almost within the normal range in this period. In contrast, serum 1,25-dihydroxyvitamin D levels increased with gestational age and were above the normal range during pregnancy. After delivery, they fell rapidly and significantly $(P<0 \cdot 01)$ to the normal range. The levels of serum bone-specific alkaline phosphatase, one of the markers of bone formation, increased with gestational age.
\end{abstract}

After delivery, these levels were further increased at 1 month postpartum. The levels at 1 month postpartum were significantly higher than those at $8-11$ and $22-30$ weeks of pregnancy $(P<0.01$ and $P<0 \cdot 05$ respectively). The levels of serum C-terminal telopeptides of type I collagen, one of the markers of bone resorption, did not change during pregnancy. After delivery, they rapidly and significantly $(P<0 \cdot 01)$ rose at 4 days postpartum, and had then fallen by 1 month postpartum. Circulating OPG/ OCIF levels gradually increased with gestational age and significantly $(P<0 \cdot 01)$ increased immediately before delivery to $1.40 \pm 0.53 \mathrm{ng} / \mathrm{ml}$ (means \pm s.D.) compared with those in the non-pregnant, non-lactating controls $(0.58 \pm 0.11 \mathrm{ng} / \mathrm{ml})$. After delivery, they fell rapidly to $0 \cdot 87 \pm 0 \cdot 27 \mathrm{ng} / \mathrm{ml}$ at 4 days postpartum and had fallen further by 1 month postpartum.

These results suggest that the fall in OPG/OCIF levels may be partially connected with the marked acceleration of bone resorption after delivery.

Journal of Endocrinology (2002) 174, 353-359

\section{Introduction}

The structure and volume of bone is maintained by a continued and coordinated remodeling that involves bone resorption and subsequent bone formation. Estrogen deficiency in women, such as at menopause, is a major trigger of the changes in bone metabolism and causes the loss of bone density (Lufkin et al. 1992, Raize \& Shoukri 1993). Some physiological states such as pregnancy or lactation also induce dynamic changes in bone and calcium metabolism in women. During pregnancy, especially in the third trimester, considerable amounts of calcium are transported from mother to fetus through the placenta for normal bone mineralization in the growing fetus. During lactation, calcium losses in mothers are greater than those during pregnancy. Nursing mothers provide an average of 200-250 mg calcium/day to their infants, sometimes as much as $400 \mathrm{mg} /$ day. In order to satisfy the increased demands for calcium, maternal metabolism of bone and calcium changes dynamically during pregnancy and lactation.

Recently, a novel cytokine termed osteoprotegerin (OPG)/osteoclastogenesis-inhibitory factor (OCIF) was purified from the conditioned medium of human embryonic lung fibroblasts IMR-90 (Tsuda et al. 1997). The administration of recombinant OPG/OCIF leads to an increase in bone mineral density, associated with a decrease in the number of active osteoclasts in normal rats (Yasuda et al. 1998), and it also prevents bone loss and restores bone strength in ovariectomized rats by reducing bone resorption (Simonet et al. 1997). It is further revealed that OPG/OCIF circulates in human blood mainly as a monomer, that serum concentrations of OPG/OCIF increase with age in both healthy men and women, and that 
these concentrations are significantly higher in postmenopausal women with osteoporosis than in age-matched normal controls (Yano et al. 1999).

However, other physiological profiles or regulatory mechanisms of OPG/OCIF in women have not been clarified. To define the effects of pregnancy and lactation on circulating OPG/OCIF in mothers, we studied the changes in the levels of OPG/OCIF in the maternal circulation during pregnancy and after delivery. We further analyzed the relations between the circulating OPG/OCIF and calcium-regulating hormones or biochemical markers of bone turnover in mothers.

\section{Materials and Methods}

\section{Experimental subjects}

Fourteen Japanese women who attended the Tokushima University Hospital from an early stage of pregnancy, aged 23-36 years (mean \pm S.D. 29.5 $\pm 4 \cdot 4$ ), with body mass indices (BMI) ranging from $17 \cdot 1$ to $27 \cdot 9 \mathrm{~kg} / \mathrm{m}^{2}$ (mean \pm S.D., $21 \cdot 5 \pm 3 \cdot 8$ ) were studied during pregnancy and after delivery after providing informed consent.

None of them had any disorders that affected their metabolism of calcium or bone, any history of endocrine, renal or liver illness, hypertension of pregnancy or gestational diabetes, and none was regularly taking medications or using hormonal contraceptives. All had had singleton pregnancies lasting 37 weeks or more and intended to breastfeed for at least 6 months.

\section{Collection of blood samples}

Fasting blood samples were collected during pregnancy (at 8-11 weeks, at 22-30 weeks, at 35-36 weeks of pregnancy and immediately before delivery, i.e. after the onset of labor pain) and after delivery (at 4 days and at 1 month postpartum). Serum was immediately separated after blood collection and promptly frozen at $-40{ }^{\circ} \mathrm{C}$ until assay.

Additional blood samples were collected from the follicular phase of 14 women who had a normal menstrual cycle, aged 21-39 years (mean \pm s.D., $29 \cdot 5 \pm 5 \cdot 0$ ), with BMI ranging from 16.6 to $27.5 \mathrm{~kg} / \mathrm{m}^{2}$ (mean \pm S.D., $21 \cdot 5 \pm 2 \cdot 5)$, for the age- and BMI-matched controls of circulating OPG/OCIF after providing informed consent.

\section{Determination of minerals, calcium-regulating hormones and bone turnover markers}

Total calcium, albumin and phosphorus concentrations in sera were determined by an automatic analyzer (Olympus AU 2000 for calcium and albumin; Olympus AU 800 for phosphorus, Olympus Promarketing Inc., Tokyo, Japan). Before statistical analysis, all serum calcium values were adjusted for serum albumin concentration.
Serum intact parathyroid hormone (PTH) was measured by a two-site immunoradiometric assay (IRMA) (Nichols Research Institute, San Juan Capistrano, CA, USA), with a normal range of $10-65 \mathrm{pg} / \mathrm{ml}$ and an assay sensitivity of $1 \mathrm{pmol} / \mathrm{l}$. Serum 1,25-dihydroxyvitamin D $\left(1,25(\mathrm{OH})_{2} \mathrm{D}\right)$ was determined with a radioimmunoassay (RIA) kit (Immunodiagnostic Systems Ltd, Boldon, UK).

Markers of bone formation used in this study were osteocalcin and bone-specific alkaline phosphatase (BSAP). Serum osteocalcin was measured with an IRMA kit (Mitsubishi Chemical, Tokyo, Japan), with a normal range of $3 \cdot 1-12 \cdot 7 \mathrm{ng} / \mathrm{ml}$ and an assay sensitivity of $1 \mathrm{ng} /$ $\mathrm{ml}$. Serum BSAP was measured using an enzyme-linked immunosorbent assay (ELISA) kit (Metra Biosystems Inc., Palo Alto, CA, USA). Average intra-assay variability was $<5 \%$ for all measures of bone formation. A marker of bone resorption was C-terminal telopeptides of type I collagen (1 CTP) determined using an RIA kit (Orion Diagnostica, Espoo, Finland). Average intra-assay variability was $<10 \%$.

\section{Measurement of circulating OPG/OCIF}

Serum OPG/OCIF levels were determined using an ELISA kit (Cosmo Bio Co., Tokyo, Japan). Briefly, a serum sample was diluted ten times with specimen diluent supplied in this kit. The diluted specimen was pipetted into a reaction well coated with anti-human OPG/OCIF monoclonal antibody. During the incubation time, the anti-human OPG/OCIF monoclonal antibody immunologically binds the OPG/OCIF in the patient's specimen. After thorough washing, another anti-human OPG/OCIF monoclonal antibody conjugated with horseradish peroxidase was added to the reaction well and incubated with the coated antibody-antigen complex. The conjugated antibody binds to the OPG/OCIF antigen on the complex and makes an antibody-antigen-antibody complex by two steps (two-stepped sandwich method). After the second washing step, o-phenylenediamine solution containing hydrogen peroxide was added to the reaction well and, during an incubation period, a yellow color developed in proportion to the amount of enzyme conjugate bound to the well. The enzyme reaction was stopped by the addition of acid. The absorbance value of the specimens was determined using a spectrophotometer with the wavelength set at $492 \mathrm{~nm}$. The assay range was $31 \cdot 25-500 \mathrm{pg} /$ $\mathrm{ml}$. Average intra-assay variability was less than $10 \%$.

\section{Statistical analysis}

Data are expressed as the means \pm S.D. For the analyses of clinical and laboratory data, non-parametric analysis of variance (Kruskall-Wallis test) was used because of the presence of non-homogeneous variances across the group. The Scheffe's multiple range test was used for post hoc comparisons. Correlations between the serum 


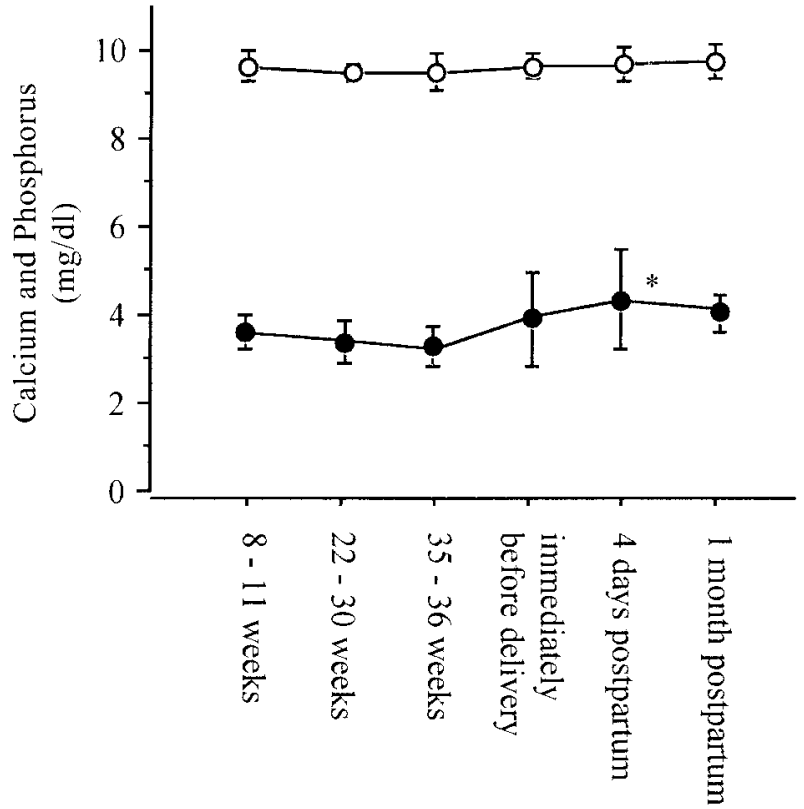

Figure 1 Mean \pm S.D. changes in the levels of serum calcium and phosphorus during pregnancy and lactation in 14 women. The levels of serum calcium $(O)$ did not change, while those of serum phosphorus ( ) at 4 days postpartum were significantly $\left({ }^{*} P<0 \cdot 05\right)$ higher than those at 22-30 and 35-36 weeks of pregnancy.

concentrations of OPG/OCIF and calcium-regulating hormones or biochemical markers of bone metabolism were determined by linear regression analysis. All $P$ values $\leq 0 \cdot 05$ were considered statistically significant. Analyses were carried out using a Stat Works program (Cricket Software, Inc., Philadelphia, PA, USA).

\section{Results}

Changes in minerals and calcium-regulating hormones

The changes in the levels of serum calcium and phosphorus during pregnancy and lactation are shown in Fig. 1. The levels of serum calcium did not change, while those of serum phosphorus at 4 days postpartum were significantly $(P<0 \cdot 05)$ higher than those at $22-30$ and 35-36 weeks of pregnancy. The changes in the levels of circulating calcium-regulating hormones during pregnancy and lactation are shown in Fig. 2. The levels of serum intact PTH did not change statistically and were almost within the normal range. In contrast, the levels of serum $1,25(\mathrm{OH})_{2} \mathrm{D}$ increased with gestational age to $108 \cdot 3 \pm 20 \cdot 9 \mathrm{pg} / \mathrm{ml}$ at 35-36 weeks and were above the normal range over the pregnancy. After delivery, they fell rapidly and significantly $(P<0.01)$ at 4 days postpartum to the normal range.

\section{Changes in markers of bone formation and resorption}

The changes in the levels of the markers of bone formation and resorption during pregnancy and lactation are shown
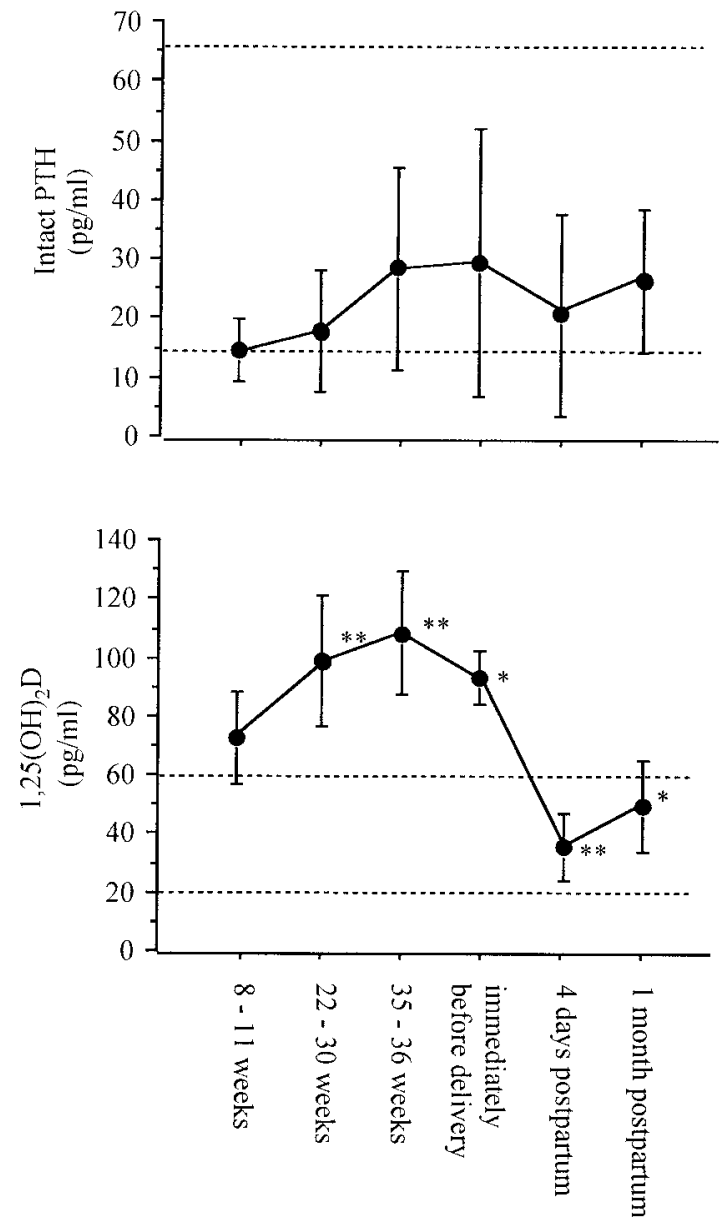

Figure 2 Mean \pm S.D. changes in the levels of circulating calciumregulating hormones during pregnancy and lactation in 14 women. The standard levels are between the dotted lines. Serum intact parathyroid hormonal (PTH) levels did not change significantly and were almost within the normal range in this period. In contrast, the levels of serum $1,25(\mathrm{OH})_{2} \mathrm{D}$ increased with gestational age to 35-36 weeks and were above the normal range during pregnancy. After delivery, they fell rapidly and significantly to the normal range. ${ }^{*} P<0 \cdot 05,{ }^{* *} P<0 \cdot 01$ compared with $8-11$ weeks.

in Fig. 3. Serum BSAP levels increased with gestational age. After delivery, these levels remained at the same level at 4 days postpartum, then further increased at 1 month postpartum. These levels at 1 month postpartum were significantly higher than those at 8-11 and 22-30 weeks of pregnancy $(P<0 \cdot 01$ and $P<0 \cdot 05$ respectively). Serum osteocalcin levels were low during pregnancy, and those in 12 of 14 samples at $22-30$ weeks and those in nine immediately before delivery were below the sensitivity of the assay. They then continued to rise after delivery to 1 month postpartum. These levels at 1 month postpartum were significantly higher than those at all stages of pregnancy $(P<0 \cdot 01)$ and at 4 days postpartum $(P<0 \cdot 05)$. 
Serum levels of 1 CTP did not change through pregnancy and were $5 \cdot 0 \pm 1 \cdot 2 \mathrm{ng} / \mathrm{ml}$ immediately before delivery. After delivery, they rapidly and significantly $(P<0 \cdot 01)$ rose to $28 \cdot 9 \pm 8 \cdot 1 \mathrm{ng} / \mathrm{ml}$ at 4 days postpartum, then fell by 1 month postpartum to $8.5 \pm 1.8 \mathrm{ng} / \mathrm{ml}$.

\section{Changes in OPG/OCIF}

The levels of serum OPG/OCIF during pregnancy and lactation and in the controls are shown in Fig. 4. Serum
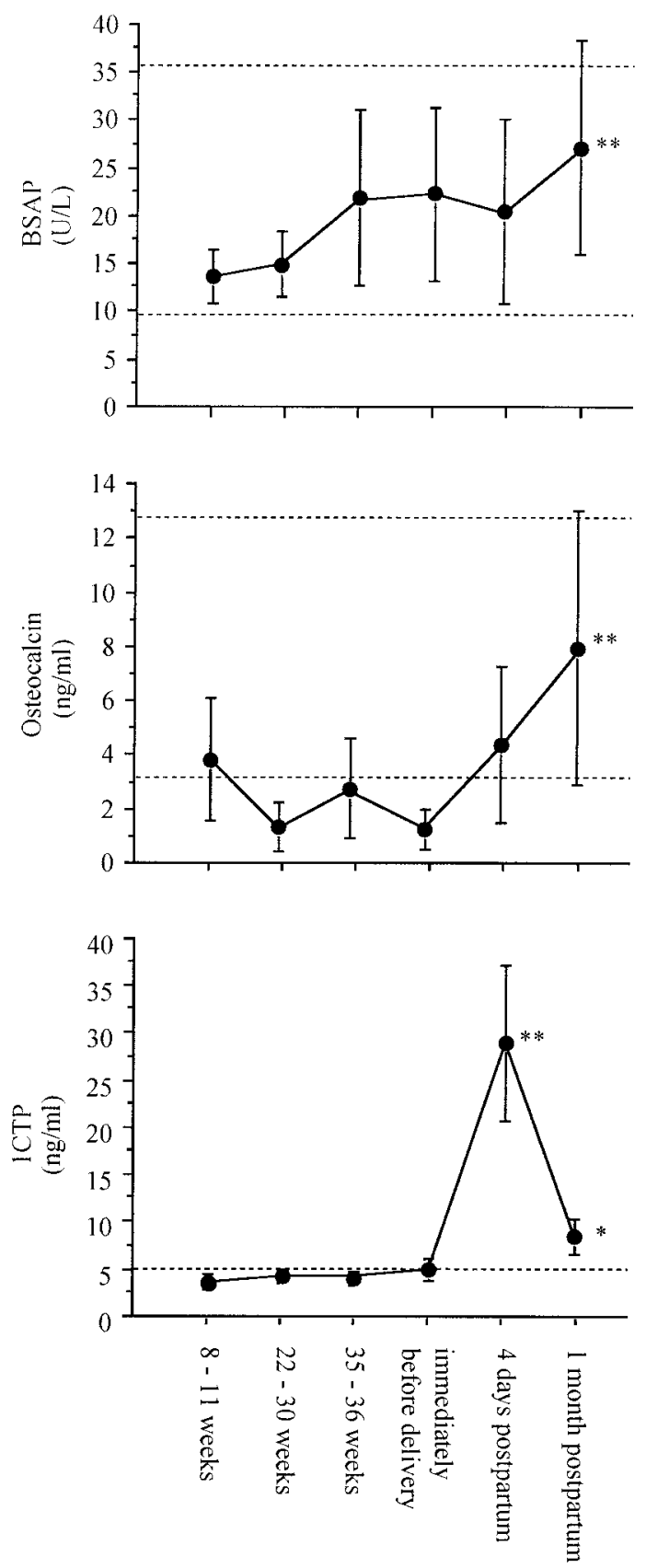

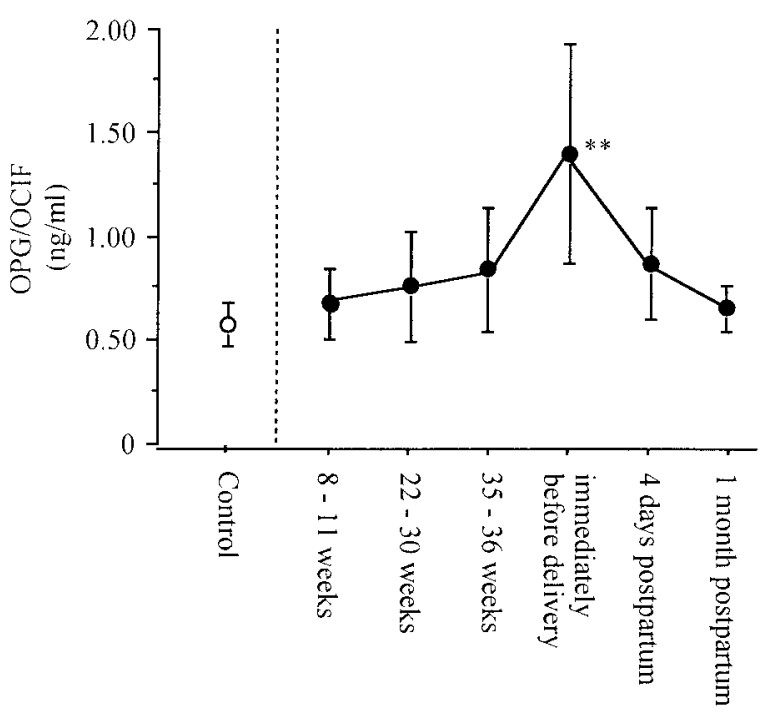

Figure 4 Mean \pm S.D. changes in the levels of circulating osteoprotegerin/osteoclastogenesis-inhibitory factor (OPG/OCIF) during pregnancy and lactation in 14 women and in the controls (14 non-pregnant, non-lactating women). Serum OPG/OCIF levels steadily increased with gestational age during pregnancy. The levels immediately before delivery were significantly $\left({ }^{* *} P<0 \cdot 01\right)$ higher than those in the controls. After delivery, they fell rapidly at 4 days postpartum and decreased furthermore to 1 month postpartum.

OPG/OCIF levels in the controls were $0.58 \pm 0 \cdot 11 \mathrm{ng} /$ $\mathrm{ml}$. They steadily increased with gestational age during pregnancy. These levels immediately before delivery were $1.40 \pm 0.53 \mathrm{ng} / \mathrm{ml}$ and were significantly $(P<0.01)$ higher than those in the controls. After delivery, they fell rapidly to $0 \cdot 87 \pm 0 \cdot 27 \mathrm{ng} / \mathrm{ml}$ at 4 days postpartum and decreased furthermore to 1 month postpartum.

\section{Relationship between circulating OPG/OCIF and bone turnover markers or calcium-regulating hormones}

OPG/OCIF values in the maternal circulation did not correlate with any single parameter of the bone turnover

Figure 3 Mean \pm S.D. changes in the levels of the markers of bone formation and resorption during pregnancy and lactation in 14 women. The standard levels are between the dotted lines for bonespecific alkaline phosphatase (BSAP) and osteocalcin, and under the dotted line for C-terminal telopeptides of type 1 collagen (1 CTP). Serum BSAP levels increased with gestational age. After delivery, these remained at the same level at 4 days postpartum, then further increased at 1 month postpartum. The levels at 1 month postpartum were significantly higher than those at 8-11 and 22-30 weeks of pregnancy $(P<0.01$ and $P<0.05$ respectively). Serum osteocalcin levels were low during pregnancy, and those in 12 of 14 samples at 22-30 weeks and those in nine immediately before delivery were below the sensitivity of the assay. The values below the sensitivity of the assay were estimated as $1 \mathrm{ng} / \mathrm{ml}$. After delivery they continued to rise to 1 month postpartum. Serum levels of 1 CTP did not change through pregnancy. After delivery, they rapidly and significantly rose at 4 days postpartum, then fell by 1 month postpartum. ${ }^{*} P<0 \cdot 05,{ }^{* *} P<0 \cdot 01$ compared with $8-11$ weeks. 
markers or calcium-regulating hormones (data not shown).

\section{Discussion}

Osteoporosis is a metabolic bone disease and it is associated with the imbalance between bone resorption by osteoclasts and bone formation by osteoblasts. Postmenopausal estrogen deficiency and aging are the two main factors which cause osteoporosis in women. In addition, particular physiological states such as pregnancy or lactation induce dynamic changes in maternal calcium metabolism. During these physiological states, the demands for calcium are large because of the growing fetal and infantile skeletons. The loss of calcium from a mother to a fetus through the placenta is about $30 \mathrm{~g}$ over pregnancy (Pitkin 1985). In contrast, the loss of calcium from a mother to an infant is about $40 \mathrm{~g}$ during 6 months of lactation. The loss of bone density in the spine and hip averages $4-6 \%$ during the first 6 months of lactation (Hayslip et al. 1989, Affinito et al. 1996, Lopez et al. 1996, Kalkwarf et al. 1997). Calcium is mobilized from the maternal skeleton to maintain serum calcium concentrations within a narrow range and to support milk production. Although the demands for calcium in the late stages of pregnancy and lactation are similar at approximately $300 \mathrm{mg} /$ day (Laskey et al. 1998), the loss of bone density is none or little during pregnancy (Kent et al. 1990, 1991) while it is significant in lactation (Atkinson \& West 1970, Chan et al. 1982). One probable reason why pregnancy does not affect maternal bone density is the increased capacity of intestinal calcium absorption due to the increased circulating $1,25(\mathrm{OH})_{2} \mathrm{D}$ (Kent et al. 1990, 1991). Another reason may be the protective effects of increased circulating estrogen on the bone. However, other details of the mechanisms are still not known.

A novel cytokine OCIF, a secreted protein consisting of 380 amino acids, was isolated as a basic glycoprotein with apparent molecular weights of $60 \mathrm{kDa}$ for a monomer and $120 \mathrm{kDa}$ for the homodimer (Tsuda et al. 1997) and is also called OPG. cDNA encoding OCIF has been cloned, and analysis of the cDNA sequence revealed that OCIF is a soluble member of the tumor necrosis factor (TNF) receptor family (Yasuda et al. 1998). OPG/OCIF competes with the receptor activator of NF- $\mathrm{KB}$ for binding to osteoclast differentiation factor, and it inhibits osteoclast maturation in vivo and in vitro. Bekker et al. (2001) showed that a single s.c. injection of OPG leads to a rapid decrease in urinary $\mathrm{N}$-telopeptide and to a delayed decrease in BSAP (Yano et al. 1999). Yano et al. (1999) reported that OPG/OCIF circulates in human blood mainly as a monomer (Bekker et al. 2001). Because the ELISA kit for the determination of OPG/OCIF used in this study can measure monomeric and dimeric OPGs/OCIFs equally, it is a suitable assay for the determination of serum concentrations of OPG/OCIF. It has also been reported that serum concentrations of OPG/OCIF increase with age in both healthy men and women, and that these concentrations are significantly higher in postmenopausal women with osteoporosis than in age-matched normal controls (Yano et al. 1999). Browner et al. (2001) reported that serum OPG levels in elderly women are associated with diabetes and with cardiovascular mortality, but not with baseline bone mineral density or with subsequent strokes or fractures. It was also reported that in men more than 40 years of age serum concentrations of OPG were negatively correlated with urinary excretion of total deoxypyridinoline (Dpd), but not with biochemical markers of bone formation (Szulc et al. 2001). Other details of the profiles of serum OPG/OCIF in women are still not known. We therefore examined the changes in the serum concentrations of OPG/OCIF during pregnancy and lactation.

Our results revealed that the concentrations of serum OPG/OCIF in mothers steadily increased during pregnancy and the levels immediately before delivery were about 2.5 times as high as those in non-pregnant, nonpuerperal women. Then they fell rapidly and significantly after delivery. It has been reported that the concentration of circulating OPG/OCIF in the mouse markedly increases during pregnancy (Yano et al. 2001). From these results, it can be suggested that circulating OPG/OCIF may play an important role in bone metabolism during pregnancy in mammals. Simonet et al. (1997) reported that OPG/OCIF mRNA expression in the placenta is strong in the mouse and the human, and suggested that the sequential expression of the OPG/OCIF gene in maternal tissues such as decidua and placenta may play a role in the control of bone metabolism in a pregnant female. The main reason that circulating OPG/OCIF levels were high during pregnancy from this point is thought to be production by the placenta. The levels of circulating OPG/OCIF rose sharply from 35-36 weeks to immediately before delivery. This might be a result of the larger loss of calcium in mothers in the late stages of pregnancy.

Our study also showed that serum levels of BSAP, one of the markers of bone formation, increased during pregnancy and were above the normal range during pregnancy. After delivery, these levels remained at the same level at 4 days postpartum, then further increased at 1 month postpartum. It is widely recognized that osteocalcin is a sensitive and specific clinical marker of bone turnover in most situations (Price et al. 1980, Gundberg et al. 1983). However, serum osteocalcin measurements are not useful as a marker of bone turnover during pregnancy because serum osteocalcin may be destroyed by a placental mechanism (Rodin et al. 1989). In this study, serum osteocalcin levels were low during pregnancy, and especially those in 12 of 14 samples at $22-30$ weeks and those in nine immediately before delivery which were below the sensitivity of the assay. These results are consistent with previous reports (Martinez et al. 1985, Cole et al. 1987, Rico et al. 1987, Rodin et al. 1989). Serum levels of 1 
CTP, one of the markers of bone resorption, did not change through pregnancy. These levels remained within the standard level until 35-36 weeks of pregnancy and were slightly over the standard level immediately before delivery. After delivery, they rapidly and markedly rose at 4 days postpartum. Naylor et al. (2000) reported that the levels of urinary pyridinoline (Pyd) and Dpd, which are the urinary markers of bone resorption, were higher during pregnancy than those in the non-pregnant, nonlactating period and increased with gestational age. After delivery, these levels further increased (Naylor et al. 2000). During pregnancy, the changes in the levels of serum 1 CTP were quite different from those of urinary Pyd and Dpd. Serum 1 CTP may be decomposed to some degree by a placental mechanism the same as serum osteocalcin. In our results and those of Naylor et al. (2000), bone formation and resorption were accelerated during pregnancy, especially in the late stages. After delivery, bone resorption markedly rose at 4 days postpartum and fell at 1 month postpartum, while bone formation remained increased at 4 days postpartum and was still increased at 1 month postpartum. It has been reported that calcium supplementation cannot prevent the loss of bone density and does not affect calcium homeostasis and bone turnover in lactating women (Kalkwarf et al. 1997, 1999). Therefore, loss of calcium induced by lactation may not be the only cause of the loss of bone density in lactating women. Lactating women show lower estrogen levels, higher prolactin levels and higher PTH-related peptide levels than non-lactating women (Sowers et al. 1996). These conditions must be the cause of the loss of bone density during lactation. Other triggers by which bone resorption accelerates after delivery are the decrease of $1,25(\mathrm{OH})_{2} \mathrm{D}$ and may be the fall of OPG/OCIF, according to our results.

In our analyses of cord blood profiles, the levels of calcium, phosphorus and the biomarkers of both bone formation and resorption were quite high, while those of intact PTH were low and those of $1,25(\mathrm{OH})_{2} \mathrm{D}$ were within the normal range. Mean OPG/OCIF levels in cord blood were $0.35 \mathrm{ng} / \mathrm{ml}$ and lower than those in adult women (data not shown). Low levels of OPG/OCIF may be one of the factors of high bone turnover in fetuses.

In summary, we have revealed changes in the levels of OPG/OCIF as well as in those of calcium-regulating hormones and biochemical markers of bone turnover in maternal circulation during pregnancy and lactation. We found that the fall in OPG/OCIF levels may be partially connected with the marked acceleration of bone resorption after delivery. Further studies are necessary to elucidate the detailed functions of OPG/OCIF on bone metabolism during pregnancy and lactation.

\section{References}

Affinito P, Tommaselli GA, di Carlo C, Guida F \& Nappi C 1996 Changes in bone mineral density and calcium metabolism in breastfeeding women: a one year follow-up study. Journal of Clinical Endocrinology and Metabolism 81 2314-2318.

Atkinson PJ \& West RR 1970 Loss of skeletal calcium in lactating women. Journal of Obstetrics and Gynaecology of the British Commonwealth 77 555-560.

Bekker PJ, Holloway D, Nakanishi A, Arrighi M, Leese PT \& Dunstan CR 2001 The effect of a single dose of osteoprotegerin in postmenopausal women. Journal of Bone and Mineral Research 16 $348-360$.

Browner WS, Lui LY \& Cummings SR 2001 Associations of serum osteoprotegerin levels with diabetes, stroke, bone density, fractures, and mortality in elderly women. Journal of Clinical Endocrinology and Metabolism 86 631-637.

Chan GM, Ronald N, Slater P, Hollis J \& Thomas MR 1982 Decreased bone mineral status in lactating adolescent mothers. Journal of Pediatrics 101 767-770.

Cole DE, Gundberg CM, Stirk LJ, Atkinson SA, Hanley DA, Ayer LM \& Baldwin LS 1987 Changing osteocalcin concentrations during pregnancy and lactation: implications for maternal mineral metabolism. Journal of Clinical Endocrinology and Metabolism 65 290-294.

Gundberg CM, Lian JB, Gallop PM \& Steinberg JJ 1983 Urinary gamma-carboxyglutamic acid and serum osteocalcin as bone markers: studies in osteoporosis and Paget's disease. Journal of Clinical Endocrinology and Metabolism 57 1221-1225.

Hayslip CC, Klein TA, Wray HL \& Duncan WE 1989 The effects of lactation on bone mineral content in healthy postpartum women. Obstetrics and Gynecology 73 588-592.

Kalkwarf HJ, Specker BL, Bianchi DC, Ranz J \& Ho M 1997 The effect of calcium supplementation on bone density during lactation and after weaning. New England Journal of Medicine 337 523-528.

Kalkwarf HJ, Specker BL \& Ho M 1999 Effects of calcium supplementation on calcium homeostasis and bone turnover in lactating women. Journal of Clinical Endocrinology and Metabolism 84 464-470.

Kent GN, Price RI, Gutteridge DH, Smith M, Allen JR, Bhagat CI, Barnes MP, Hickling CJ, Retallack RW, Wilson SG, Devlin RD, Davies C \& St John A 1990 Human lactation: forearm trabecular bone loss, increased bone turnover, and renal conservation of calcium and inorganic phosphate with recovery of bone mass following weaning. Journal of Bone and Mineral Research 5 361-369.

Kent GN, Price RI, Gutteridge DH, Rosman KJ, Smith M, Allen JR, Hickling CJ \& Blakeman SL 1991 The efficiency of intestinal calcium absorption is increased in late pregnancy but not in established lactation. Calcified Tissue International 48 293-295.

Laskey MA, Prentice A, Hanratty LA, Jarjou LM, Dibba B, Beavan SR \& Cole TJ 1998 Bone changes after 3 mo of lactation: influence of calcium intake, breast-milk output, and vitamin D-receptor genotype. American Journal of Clinical Nutrition 67 685-692.

Lopez JM, Gonzalez G, Reyes V, Campino C \& Diaz S 1996 Bone turnover and density in healthy women during breastfeeding and after weaning. Osteoporosis International 6 153-159.

Lufkin EG, Wahner HW, O'Fallon WM, Hodgson SF, Kotowicz MA, Lane AW, Judd HL, Caplan RH \& Riggs BL 1992 Treatment of postmenopausal osteoporosis with transdermal estrogen. Annals of Internal Medicine 117 1-9.

Martinez ME, de Pedro C, Catalan P, Salinas M, Balaguer G \& Ordas J 1985 Levels of osteocalcin in normal pregnancy. American Journal of Obstetrics and Gynecology 153 708-709.

Naylor KE, Iqbal P, Fledelius C, Fraser RB \& Eastell R 2000 The effect of pregnancy on bone density and bone turnover. Journal of Bone and Mineral Research 15 129-137.

Pitkin RM 1985 Calcium metabolism in pregnancy and the perinatal period: a review. American Journal of Obstetrics and Gynecology 151 99-109. 
Price PA, Parthemore JG \& Deftos LJ 1980 New biochemical marker for bone metabolism. Measurement by radioimmunoassay of bone GLA protein in the plasma of normal subjects and patients with bone disease. Journal of Clinical Investigation 66 878-883.

Raize LG \& Shoukri KC 1993 Pathogenesis of osteoporosis. In Physiology and Pharmacology of Bone, pp 299-323. Eds GR Mundy \& TJ Martin. Heidelberg: Springer-Verlag.

Rico H, Cabrane JA, Farinas M, Costalles C, Martin F \& Gaaebelt K 1987 Serum osteocalcin at delivery. Journal of Obstetrics and Gynecology 7 259-261.

Rodin A, Duncan A, Quartero HW, Pistofidis G, Mashiter G, Whitaker K, Crook D, Stevenson JC, Chapman MG \& Fogelman I 1989 Serum concentrations of alkaline phosphatase isoenzymes and osteocalcin in normal pregnancy. Journal of Clinical Endocrinology and Metabolism 68 1123-1127.

Simonet WS, Lacey DL, Dunstan CR, Kelley M, Chang MS, Luthy R, Nguyen HQ, Wooden S, Bennett L, Boone T, Shimamoto G, DeRose M, Elliott R, Colombero A, Tan HL, Trail G, Sullivan J, Davy E, Bucay N, Renshaw-Gegg L, Hughes TM, Hill D, Pattison W, Campbell P \& Boyle WJ 1997 Osteoprotegerin: a novel secreted protein involved in the regulation of bone density. Cell 89 309-319.

Sowers MF, Hollis BW, Shapiro B, Randolph J, Janney CA, Zhang D, Schork A, Crutchfield M, Stanczyk F \& Russell-Aulet M 1996 Elevated parathyroid hormone-related peptide associated with lactation and bone density loss. Journal of the American Medical Association 276 549-554.

Szulc P, Hofbauer LC, Heufelder AE, Roth S \& Delmas PD 2001 Osteoprotegerin serum levels in men: correlation with age, estrogen, and testosterone status. Journal of Clinical Endocrinology and Metabolism 86 3162-3165.

Tsuda E, Goto M, Mochizuki S, Yano K, Kobayashi F, Morinaga T \& Higashio K 1997 Isolation of a novel cytokine from human fibroblasts that specifically inhibits osteoclastogenesis. Biochemical and Biophysical Research Communications 234 137-142.

Yano K, Tsuda E, Washida N, Kobayashi F, Goto M, Harada A, Ikeda K, Higashio K \& Yamada Y 1999 Immunological characterization of circulating osteoprotegerin/osteoclastogenesis inhibitory factor: increased serum concentrations in postmenopausal women with osteoporosis. Journal of Bone and Mineral Research 14 518-527.

Yano K, Shibata O, Mizuno A, Kobayashi F, Higashio K, Morinaga T \& Tsuda E 2001 Immunological study on circulating murine osteoprotegerin/osteoclastogenesis inhibitory factor (OPG/OCIF): possible role of OPG/OCIF in the prevention of osteoporosis in pregnancy. Biochemical and Biophysical Research Communications 288 $217-224$

Yasuda H, Shima N, Nakagawa N, Mochizuki SI, Yano K, Fujise N, Sato Y, Goto M, Yamaguchi K, Kuriyama M, Kanno T, Murakami A, Tsuda E, Morinaga T \& Higashio K 1998 Identity of osteoclastogenesis inhibitory factor (OCIF) and osteoprotegerin (OPG): a mechanism by which OPG/ OCIF inhibits osteoclastogenesis in vitro. Endocrinology 1391329 1337.

Received in final form 30 April 2002

Accepted 1 May 2002 